05.1

\title{
Пороговые режимы динамического деформирования алюминиевого сплава 1565
}

\author{
() А.К. Диваков ${ }^{1}$, Н.И. Жигачева ${ }^{1}$, Г.В. Коновалов ${ }^{1}$, Ю.И. Мещеряков ${ }^{1, \uparrow, ~ Е . П . ~ О с о к и н ~}{ }^{2}$ \\ ${ }^{1}$ Институт проблем машиноведения РАН, Санкт-Петербург, Россия \\ ${ }^{2}$ ЦНИИ конструкционных материалов „Прометей“, Санкт-Петербург, Россия \\ ฯE-mail: ym38@mail.ru
}

Поступило в Редакцию 4 декабря 2018 г.

В окончательной редакции 4 декабря 2018 г.

Принято к публикации 6 декабря 2018 г.

\begin{abstract}
С целью идентификации пороговых режимов структуризации проведены две серии испытаний алюминиевого сплава 1565 в диапазоне скоростей $250-750 \mathrm{~m} / \mathrm{s}$ : ударные испытания в условиях одноосной деформации и внедрение ударников. Сопоставление данных по обеим сериям испытаний позволяет отделить лобовое сопротивление при взаимодействии удлиненного ударника с мишенью от сопротивления трения с его боковой частью. Установлено, что на боковой поверхности каверны смена масштаба структуризации происходит дважды: при скоростях 400 и $623.3 \mathrm{~m} / \mathrm{s}$, причем второй порог структуризации практически совпадает с аналогичным порогом при нагружении в условиях одноосной деформации.
\end{abstract}

DOI: 10.21883/PJTF.2019.05.47395.17624

Процессы многомасштабного высокоскоростного деформирования при соударении ударников с твердотельной мишенью включают смену механизма структурообразования [1-5]. На макроскопическом уровне смена масштабного уровня динамического деформирования проявляется в изменении характера отклика материала на ударное нагружение. На микроуровне смена масштабного уровня определяется по структурным изменениям материала мишени. При исследовании динамических деформационных процессов в твердых телах распространение получили два метода нагружения: высокоскоростное внедрение удлиненных ударников и нагружение в условиях одноосной деформации. В случае нагружения мишеней удлиненными ударниками экспериментально определяемыми характеристиками процесса являются скорость соударения и глубина внедрения ударника в мишень, дополненные данными микроструктурных исследований образцов после ударного нагружения. При ударном нагружении в условиях одноосной деформации кроме скорости ударника $U_{i m p}$ регистрируется временной профиль скорости свободной поверхности мишени $U_{f s}(t)$, что дает количественную информацию о таких характеристиках, как динамический предел текучести, порог структурной неустойчивости материала при ударном сжатии, дефект скорости на плато импульса сжатия и откольная прочность материала.

Задача исследования состоит в следующем: выяснить, совпадают ли по скорости ударного нагружения пороги структурных переходов при одноосном деформировании и при высокоскоростном внедрении удлиненных ударников; определить морфологию структуры в „допороговой“ и „запороговой“ областях скоростей деформации для двух типов ударного нагружения. Указанные сведения важны при создании материалов с заданными свойствами.
Для выполнения поставленной задачи в настоящей работе проведены две серии ударных испытаний алюминиевого сплава 1565. Первая серия испытаний высокоскоростное внедрение удлиненных ударников с плоской конфигурацией носовой части. В этой конфигурации имеют место два механизма сопротивления внедрению ударника: лобовое сопротивление плоской носовой части ударника и сопротивление трения боковой поверхности ударника. Во второй серии испытаний соударения в условиях одноосной деформации - мишень испытывает только лобовое сопротивление. Сопоставление данных по обеим сериям испытаний позволяет отделить лобовое сопротивление при взаимодействии удлиненного ударника с мишенью от сопротивления трения боковой части ударника и таким образом идентифицировать порог структурного перехода в пограничном слое каверны.

Испытания в условиях одноосной деформации выполнялись на однокаскадной легкогазовой пушке с диаметром ствола $37 \mathrm{~mm}$. Плоские мишени в виде дисков имели диаметр $52 \mathrm{~mm}$ и толщину $7 \mathrm{~mm}$. Данные о динамической прочности и пластичности материала, включая динамический предел текучести, откольную прочность и порог структурной неустойчивости при ударном сжатии, извлекаются из временно́го профиля скорости свободной поверхности мишени $U_{f s}(t)$, который регистрируется в реальном масштабе времени с помощью скоростного интерферометра [6]. На рис. 1 представлена зависимость максимального значения скорости свободной поверхности на плато импульса сжатия от скорости ударника $U_{f s \max }=f\left(U_{i m p}\right)$. Линия $U_{f s \max }=U_{i m p}$ соответствует симметричному соударению ударника и мишени, при котором акустические импедансы ударника и мишени равны $\left(\rho_{i m p} C_{i m p}=\rho_{t} C_{t}\right)$. Видно, что при скорости ударника $623.3 \mathrm{~m} / \mathrm{s}$ имеет место изменение наклона 


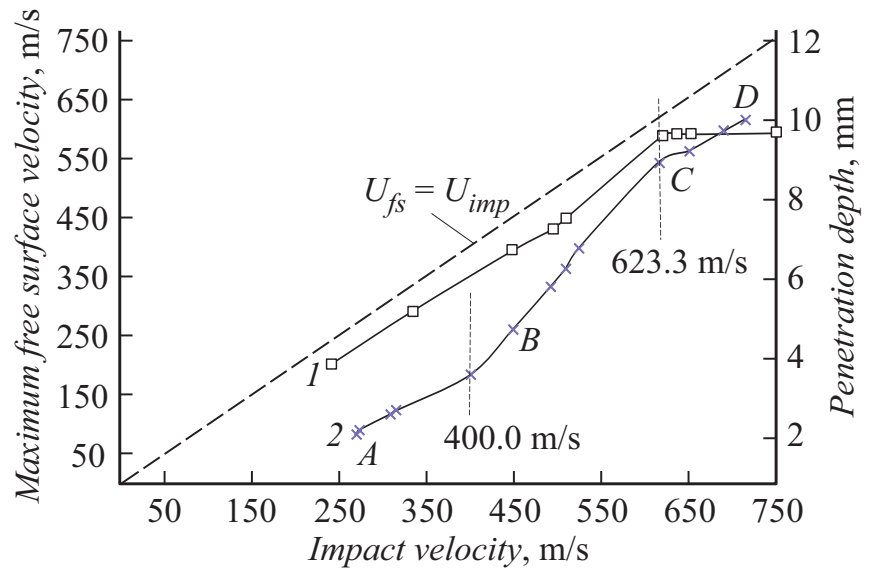

Рис. 1. Зависимость максимального значения скорости свободной поверхности $U_{f s \max }$ от скорости ударника при одноосной деформации алюминиевого сплава 1565 (1) и зависимость глубины проникания удлиненного ударника в мишень $L$ от скорости ударника (2).

зависимости $U_{f s \max }=f\left(U_{i m p}\right)$. Можно предполагать, что перелом на зависимости $U_{f s \max }=f\left(U_{i m p}\right)$ соответствует структурному переходу в материале мишени, когда в процессе динамического деформирования изменяются как тип кинематического механизма деформирования, так и масштаб структурных элементов материала мишени, в результате чего возрастают потери импульса и энергии.

Для проверки этих предположений были проведены микроструктурные исследования образцов мишеней, нагружаемых ниже и выше порога структурного перехода. Исследования проводились на поперечных разрезах мишеней с использованием оптического микроскопа „Observier.Z.1m“ после полировки и травления в смеси азотной и плавиковой кислот.

В случае нагружения в условиях одноосной деформации наиболее информативным показателем структурной перестройки является морфология разрушения в откольной зоне. На рис. 2, $a, b$ представлены две картины разрушения в откольной зоне, отвечающие скоростям ударника 400 и $636 \mathrm{~m} / \mathrm{s}$. Первая скорость соответствует „допороговой“ области динамического деформирования, а вторая - „запороговой“. Видно, что при скорости ударника ниже порога структурного перехода откольная зона состоит из серии плоских трещин, параллельных свободной поверхности мишени, что соответствует откольному разрушению по механизму расслоения (cleavage). Известно, что подобная морфология откольной зоны реализуется при однородном динамическом деформировании. При ударном нагружении выше пороговой скорости откольная зона представляет собой совокупность трещин размером 50-80 $\mu$, параллельных и перпендикулярных свободной поверхности. Такая картина разрушения в откольной зоне является результатом неоднородного динамического деформирования, проте- кающего в виде микропотоков среды вдоль направления распространения волны [7]. Отсюда можно заключить, что при скорости ударника $623.3 \mathrm{~m} / \mathrm{s}$ происходит смена механизма и масштабного уровня динамического деформирования и разрушения: вместо трещин расслоения реализуется откольная щель в форме меандра.

Эксперименты по прониканию удлиненных ударников в мишени из сплава 1565 проводились на той же установке, что и испытания в условиях одноосной деформации. Для обеспечения перпендикулярности соударения стержня и мишени стержень длиной $20 \mathrm{~mm}$ и диаметром $5 \mathrm{~mm}$ монтировался в стакан из поливинилкарбоната. Зависимость глубины проникания ударника в мишень от скорости ударника $L\left(U_{i m p}\right)$ представлена на рис. 1 вместе с кривой зависимости максимальной скорости на плато импульса сжатия при одноосной деформации. Как видно из рисунка, кривая зависимости глубины проникания от скорости ударника имеет два перелома. После первого перелома, соответствующего скорости ударника $400 \mathrm{~m} / \mathrm{s}$, наклон зависимости $L\left(U_{i m p}\right)$ возрастает, что свидетельствует об уменьшении сопротивляемости материала мишени внедрению ударника. После второго перелома при скорости ударника $623.3 \mathrm{~m} / \mathrm{s}$ наклон зависимости глубины проникания от скорости ударника, наоборот, уменьшается, что является результатом увеличения сопротивляемости материала мишени внедрению ударника.

При сопоставлении откликов мишени в двух разных схемах ударного деформирования оказывается возможным разграничить процессы структурообразования, обусловленные лобовым сопротивлением ударника и сопротивлением за счет взаимодействия ударника с боковой поверхностью каверны. На основании сопоставления кривых зависимостей порога структурообразования при одноосной деформации $U_{f s \max }=f\left(U_{i m p}\right)$ и кривой зависимости глубины проникания от скорости ударника $L\left(U_{i m p}\right)$ можно заключить, что верхний перелом на зависимости $L\left(U_{i m p}\right)$ соответствует порогу структурного перехода при лобовом взаимодействии плоской головной части ударника с мишенью. В этом случае нижний перелом на указанной зависимости соответствует взаимодействию ударника с боковой поверхностью каверны.

Структурные исследования второй партии мишеней проводились на поперечных разрезах мишеней в боковых областях каверны. Измерения микротвердости в указанных областях выполнялись на микротвердомере ПМТ-3 при нагрузке $50 \mathrm{~g}$. Структурные картины деформированного состояния материала мишени для двух скоростей ударника (400 и $714.3 \mathrm{~m} / \mathrm{s})$ представлены на рис. 3, $a, b$. Как видно из рис. 3, $a$, при скорости ударника $400 \mathrm{~m} / \mathrm{s}$ в узком слое боковой поверхности каверны шириной примерно $7.08 \mu \mathrm{m}$ имеются периодические сбросовые структуры, состоящие из наклонных полос локализованного сдвига. Расстояние между полосами локализованного сдвига составляет 4-8 $\mu \mathrm{m}$. В этой зоне величина микротвердости в среднем составила величину $1240 \mathrm{MPa}$, что в 1.4 раза выше, чем 


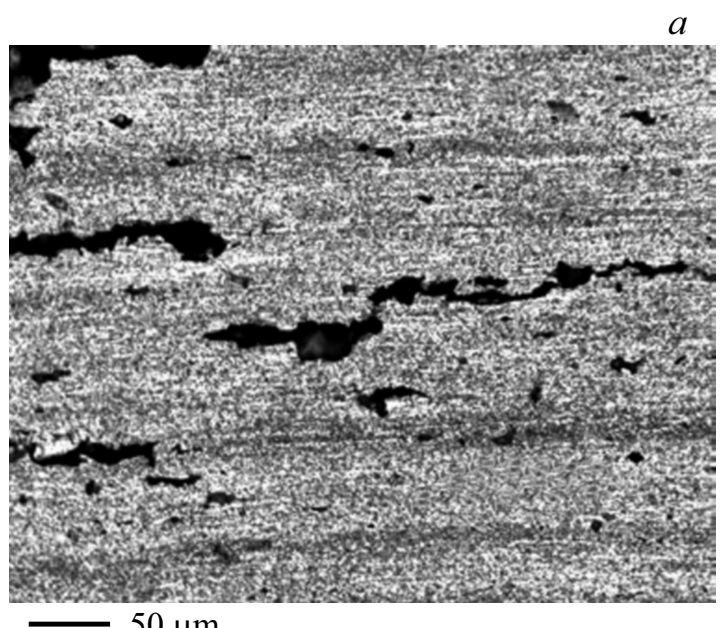

$a$

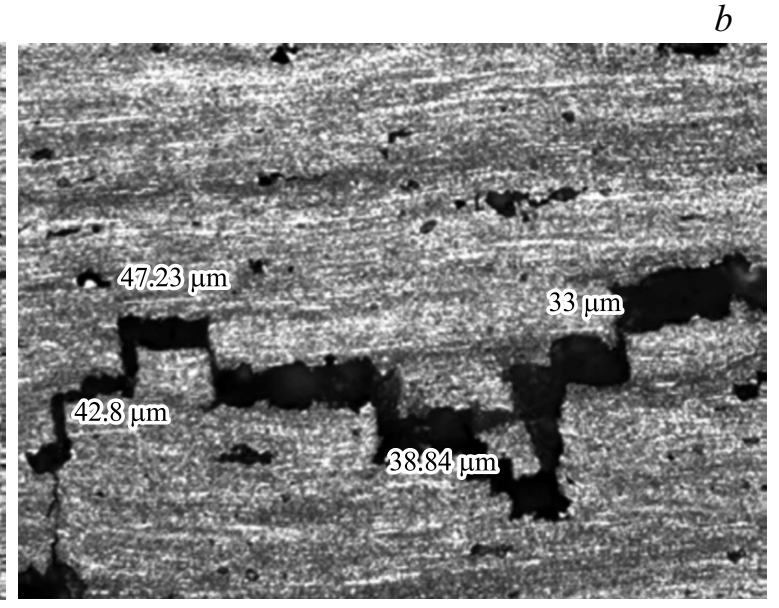

$50 \mu \mathrm{m}$

$50 \mu \mathrm{m}$

Рис. 2. Морфология откольной зоны при нагружении со скоростью 400 (a) и $636 \mathrm{~m} / \mathrm{s}(b)$.

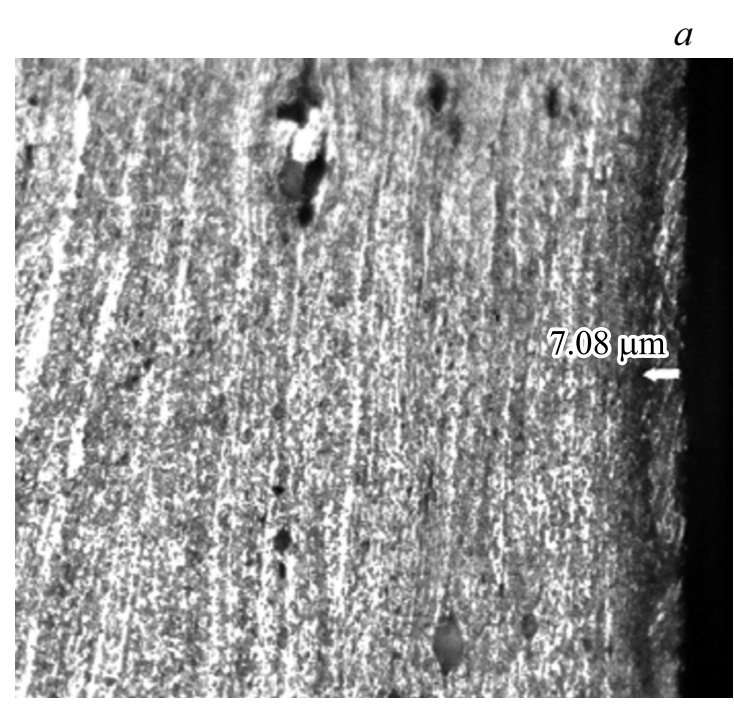

$10 \mu \mathrm{m}$

$a$

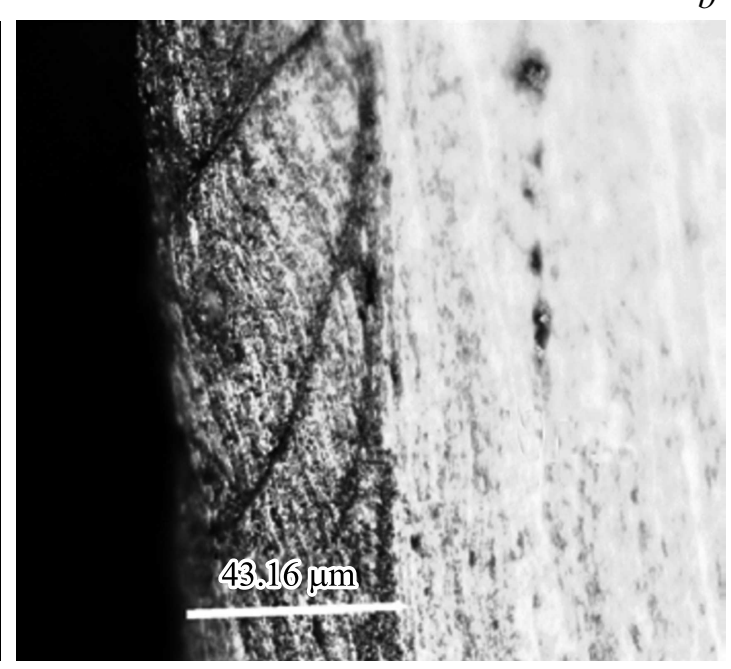

$-10 \mu \mathrm{m}$

Рис. 3. Морфология структуры боковой области каверны при скорости ударника $400 \mathrm{~m} / \mathrm{s}$ с шириной зоны неоднородной деформации $7.08 \mu \mathrm{m}(a)$ и при скорости $714.3 \mathrm{~m} / \mathrm{s}$ с шириной зоны неоднородной деформации $43.16 \mu \mathrm{m}(b)$.

для исходного материала $(880 \mathrm{MPa})$. Для зоны $B C$, соответствующей скоростям ударника $400-623.3 \mathrm{~m} / \mathrm{s}$, характерно однородное динамическое деформирование материала. В этой зоне значение микротвердости составляет величину $1140 \mathrm{MPa}$. Наконец, в третьей зоне (зона $C D$ ), соответствующей скоростям ударника выше $623.3 \mathrm{~m} / \mathrm{s}$, структура боковой поверхности каверны, так же как и первой зоне, характеризуется наличием системы полос локализованного сдвига. Однако расстояние между полосами здесь составляет величину 40-80 $\mu \mathrm{m}$, т.е. примерно на порядок больше, чем в зоне $A B$. При этом сопротивляемость материала внедрению ударника здесь увеличивается по сравнению с зоной $B C$ : кривая зависимости глубины проникания от скорости ударника становится более пологой.
Таким образом, структурные изменения в мишени как в опытах по одноосному деформированию, так в опытах по высокоскоростному внедрению ударников отчетливо демонстрируют смену масштаба, изменение морфологии структуры и сопротивляемости материала внедрению ударника.

\section{Список литературы}

[1] Беликова А.Ф., Буравова С.Н., Петров Е.В. // ЖТФ. 2013. T. 83. B. 8. C. $68-75$.

[2] Бородин И.Н., Майер А.Е. // ЖТФ. 2013. Т. 83. В. 8. С. 76 80.

[3] Власов А.С., Синани А.Б. // ЖТФ. 2017. Т. 87. В. 7. С. 1033 1039. 
[4] Соковников М.А., Биланов Д.А., Чудинов В.В., Уваров С.В., Плехов О.А., Терехина А.И., Наймарк О.Б. // Письма в ЖТФ. 2014. Т. 40. В. 23. С. $82-88$.

[5] Рыбин В.В., Переверзенщев В.Н., Свирина Ю.В. // ЖТФ. 2017. T. 87. B. 5. C. $726-735$.

[6] Златин Н.А., Мочалов М.С., Пугачев Г.С., Брагов А.М. // ЖТФ. 1973. Т. 43. В. 9. С. 1961-1964.

[7] Мещеряков Ю.И. Многомасштабные ударно-волновые процессы в твердых телах. СПб.: Нестор-История, 2018. 480 с. 